\title{
IDENTITY, PERCEPTIONS AND INSTITUTIONS: CASTE DIFFERENCES IN EARNINGS FROM SELF-EMPLOYMENT IN INDIA
}

\author{
Deepti Goel \\ Email: deepti@econdse.org \\ Department of Economics \\ Delhi School of Economics
}

\section{Ashwini Deshpande}

Email: ashwini@econdse.org

Department of Economics

Delhi School of Economics

\section{Working Paper No. 259}

http://www.cdedse.org/working-paper-frameset.htm 


\title{
Identity, Perceptions and Institutions: Caste differences in Earnings from Self- Employment in India
}

\section{Deepti Goel and Ashwini Deshpande ${ }^{1}$}

August 31, 2016

\begin{abstract}
We investigate the relationship between caste identity in India and perceptions of selfworth as measured by amounts considered as remunerative earnings from self-employment. We also investigate if institutional change such as the introduction of an employment guarantee, or change in the ruling party, alters these perceptions. Finally, we examine the relationship between caste identity and actual earnings. We find that caste identity does shape perceptions of self-worth. Lower-ranked groups perceive lower amounts as being remunerative, and also earn lower amounts. Further, institutional factors alter selfperceptions differentially for different caste groups, but in more nuanced ways than our exante beliefs.
\end{abstract}

JEL classification codes: J15, O15, P16

Keywords: Caste Discrimination, Remunerative Earnings, Political Economy

\footnotetext{
${ }^{1}$ Goel (deepti@econdse.org), corresponding author, is Assistant Professor and Deshpande (ashwini@econdse.org) is Professor at the Delhi School of Economics. Postal Address: Delhi School of Economics, Department of Economics, University of Delhi, Delhi 110007. We are grateful for comments from seminar audiences at the University of Warwick, Indian Statistical Institute, Jawaharlal Nehru University, Shiv Nadar University and the Delhi School of Economics where preliminary versions of the paper were presented. Needless to add, we are solely responsible for all errors.
} 


\section{Introduction}

Social identities, such as race, caste, gender, ethnicity and so forth, are not only strongly correlated with economic outcomes, but also shape perceptions ${ }^{2}$ including notions of self-worth. In particular, it has been suggested/ seen that individuals from marginalized, lower-ranked or discriminated against groups might have lower notions of self-worth than individuals from higher-ranked groups who are economically comparable.

In this paper, we test the effect of social identity on self-worth, and investigate whether institutional change can alter this relationship. We examine this issue by using nationally representative survey data on amounts considered as remunerative from selfemployment as a proxy for self-worth among caste groups in India that have an implicit status hierarchy. It is worth reiterating that the contemporary caste system in India consists of thousands of 'jatis' or castes that do not necessarily follow a linear hierarchy. These jatis are clubbed into four administrative categories that define data collection for the purposes of affirmative action (AA), which is mostly caste-based: Scheduled Castes (SCs) is a listing of formerly untouchable and lowest ranked jatis. Several SCs prefer to use the term "Dalit" (meaning oppressed) as a term of pride. Scheduled Tribes (STs) is a list of marginalized tribal communities and are referred to as "Adivasis", or the original inhabitants. Other Backward Classes (OBCs) is a collection of low to middle-ranking castes and communities that are eligible for AA. Everyone else is clubbed into a residual category called "Others", which is used as a proxy for upper-castes.

We focus on three major questions. First, we explore if the amounts considered as remunerative from self-employment vary in a way that lower-ranked caste groups find lower amounts to be remunerative. This might be the case if they suffer from poor self-image or low self-worth, or internalise expectations of discrimination, or be influenced by lower earnings of other workers in their caste group (compared to those in higher-ranked groups) and place an internal ceiling on what they realistically expect to earn.

Second, we assess whether institutional change could affect perceptions of caste groups differentially. Specifically, we examine two institutional changes. One, if the introduction of the Mahatma Gandhi National Rural Employment Guarantee Scheme (MGNREGS) alters perceptions in such a way that lower-caste groups find higher amounts to

\footnotetext{
${ }^{2}$ We use perceptions in the following sense: "the way in which something is regarded, understood or interpreted", rather than the more literal meaning of being aware of something through the senses.
} 
be remunerative. We would expect MGNREGS to have this effect because the scheme is specifically targeted towards poorer households that are disproportionately SC or ST. Research shows stronger positive effects of the scheme on consumption expenditure of SCST households (Klonner and Oldiges, 2014). Additionally, it might have disproportionately increased reservation earnings of targeted households. Two, we evaluate whether the caste orientation of the political party in power might differentially alter perceptions of caste groups. Specifically, we ask if the presence of a pro-lower-caste ruling party increase lowercaste expectations vis-à-vis those of upper-castes? In particular, we examine if the change from Samajwadi Party (SP) to an explicitly pro-Dalit Bahujan Samaj Party (BSP) in the north Indian state of Uttar Pradesh (UP) had a positive effect on lower-caste perceptions, compared to those of upper-castes. This would be the case if the BSP implemented pro-Dalit policies, and/or if the presence of Mayawati, BSP leader and UP Chief Minister, boosted Dalit pride and self-esteem. Through our identification strategy, we are able to comment on which of these two mechanisms might be at work.

Third, we examine how caste identity affects actual earnings, and whether institutional change affects actual earnings of caste groups differentially.

Our main results are as follows. Based on two cross-sections of data from the Employment-Unemployment Survey (EUS) of the National Sample Survey (NSS) for 2004-5 and 2009-10, we find that in 2009-10, compared to upper caste (UC) perceptions, SCs and STs perceive 9-17 percent and OBCs perceive 5-10 percent lower amounts as remunerative.

We find no evidence that MGNREGS affects SC perceptions any differently than UC perceptions, but do find a positive effect on OBC perceptions vis-à-vis UCs. ${ }^{3}$ We find that the change in the ruling party to the pro-Dalit BSP increased Dalit perceptions vis-à-vis UCs. Thus, institutional shifts do have the power to shape perceptions but the contours of the change are more complicated than our ex-ante beliefs.

The EUS does not have data on actual earnings for the self-employed. We use a unique method to ascertain actual earnings from the data (explained in Section 6), and find that in 2004-5, STs, SCs and OBCs earn amounts that are 18-30, 17-29 and 8-17 percent lower than that earned by UCs. Looking at the impact of institutional change on consumption

\footnotetext{
${ }^{3}$ The effect of MGNREGS on ST is somewhat puzzling, and we therefore abstain from making conclusive statements about it (see Section 5.2.1).
} 
expenditure (our proxy for actual earnings), ${ }^{4}$ we find that neither the MGNREGS, nor the shift to pro-Dalit BSP affects consumption expenditure of caste groups differentially.

Our data do not allow us to investigate causality in the relationship between perceptions and actual earnings, if any. We find that caste gaps in perceptions are lower than those in actual earnings, a finding that we discuss in Section 7.

The rest of the paper is organised as follows. Section 2 contains a brief review of the literature that outlines the theoretical insights from several disciplines suggesting why social identity might shape self-worth. Section 3 describes the empirical framework. Section 4 describes the data and offers summary statistics. Section 5 presents the main results related to identity, perceptions and institutional change. Section 6 presents the results related to identity, actual earnings and institutional change. Section 7 discusses the results. Section 8 offers concluding comments.

\section{Theoretical Insights: Social Identity and Self-Worth}

The idea that perceptions of self-worth vary across social groups has been explored via several disciplinary perspectives. Insights from philosophy (Foucault, 1982, 1994), sociology (Bourdieu, 1984) and social psychology (Tajfel and Turner, 1986) suggest that individual notions of self-worth are shaped by one's place in the social hierarchy. Foucault's (1982) philosophical treatise on power argues that "power relations are rooted in the system of social networks" (p. 793), and that one of the ways in which power could be exercised, i.e. power relations could be brought into being, is "by means of economic disparities" (p. 792), among other things. This would suggest that the economically marginalised would also be less powerful, and hence, might have low self-worth.

There are several illustrations of this idea in the context of gender. Studies have discussed why women have lower pay expectations, and report greater satisfaction with their current pay, despite the fact that they report making less money than men (Clayton et al 2010). Women have lower expectations compared to men because they believe they deserve less, ${ }^{5}$ which the management literature explains by differences in career paths, job inputs and so on, (Keaveny and Inderrieden, 2000), but social psychologists explain through the concept

\footnotetext{
${ }^{4}$ For 2009-10 we are unable to ascertain actual earnings for a fairly large share of our sample. We therefore use consumption expenditure, instead of actual earnings, to examine the effect of institutional change. This is explained in greater detail in section 6.

${ }^{5}$ Berkowitz et al (1987) found that respondents' satisfaction with their pay was related to what they felt they deserved, regardless of what others were paid.
} 
of "depressed entitlement", (Major and Zanna, 1994; Hogue and Yoder, 2003). While depressed entitlement was initially discussed in the context of gender pay disparities, it is now seen to operate more generally across a variety of social identities, indicating that members of low-status groups might absorb their inferiority and consequently have low selfworth, a phenomenon that is also analysed as internalisation, discussed below.

The caste system in India is an ideal site to study the role of identity in shaping selfworth as it is a system that privileges ritual status over wealth/income, ${ }^{6}$ which leads to individuals in higher ranked castes viewing themselves as higher placed compared to individuals in lower castes with similar incomes. Bros (2014) confirms this empirically using the World Values Survey data while investigating the answers to the following question: "which of these five classes do you think you belong to?" and finds that upper-caste individuals tend to place themselves in a higher class compared to lower-caste individuals who are economically similar. Caste identities shape also expectations, possibly through different notions of self-worth. Deshpande and Newman (2007) show how, among highly educated university fresh graduates, expectations about the type of job they are likely to get, the time it would take to get the job and expected salary differ between similarly qualified Dalit and upper-caste students. This could be because Dalit students have internalised expectations of labor market discrimination.

There is another reason why caste divisions are particularly well-suited to studying the issue of self-worth. Dalits have been historically associated with ritually polluting occupations, and hence used to be considered untouchable. ${ }^{7}$ For this reason, they have been deeply stigmatized. Goffman's (1963) classic work on stigma from the field of sociology has spawned research across various disciplines that shows how discrimination directly affects the "social status, psychological well-being, and physical health of the stigmatized" (Major and O'Brien, 2005, p. 396). Stigma can also affect the stigmatized even in the absence of discriminatory behaviour on the part of others, as dominant cultural stereotypes are widely known, and this knowledge "may affect behaviour through ideomotor process" (p. 397). This indicates another mechanism because of which members of stigmatised groups are likely to have low self-worth. An alternative way to see this mechanism at work would be to see if the

\footnotetext{
${ }^{6}$ For instance, Brahmins, who are at the top of the ritual purity scale, enjoy high status, even when they are not at the top of the income/wealth hierarchy (Deshpande, 2011).

${ }^{7}$ Untouchability has been legally abolished and is punishable by law, but both covert and overt instances of untouchability continue unpunished (Shah et al, 2006 and Navsarjan, 2010).
} 
reverse is true, viz., do more positive attitudes towards marginalised groups enhance their psychological well-being? Sellers et al (2006) confirm this by showing how positive attitudes towards African Americans are associated with more positive psychological functioning.

This relates to the notion of "internalisation", which is a compelling contribution from the field of social psychology. The idea that individuals from marginalised groups internalise the low worth that society places upon them is the basis of the "stereotype threat" which shows that when minorities and women are reminded of their group identities, their performance shifts in the direction of the stereotype (Steele and Aronson, 1995). This either worsens or introduces a performance gap between groups which further reinforces the negative stereotypes. Jaspal (2011) finds that negative stereotypes against them lower selfesteem among Dalits, but enhance self-esteem among members of higher-ranked castes. Pandey and Hoff (2006), in an experimental study, show how performance of Dalit students that is comparable to upper-caste students at the beginning of the experiment starts to diverge from that of upper castes when their caste status is made salient.

While this paper focuses on the role of hierarchical identities resulting in low selfworth, we should recognize that the effect of identity on self-worth is more complex. There is now a shift in social psychology towards the Stereotype Content Model (Fiske et al, 2002) which makes a distinction between internalisation and externalisation, the latter referring to the existence of stigmatizing attitudes that are not internalised by individuals in marginalised communities. Thus, depending on the context, both (internalisation as well as externalisation) or either channel might be at work, and the net result on behaviour or performance of members of marginalised groups would be more complicated depending on the relative strength of the two channels.

Economics is a relatively new entrant to this field of inquiry. Identity economics explores the role of identities in shaping individual behaviour (Akerlof and Kranton, 2011), but could conceivably be extended to the examination of the interaction of social identities and self-worth. Charles (2013), using insights from economic theory, argues that a hierarchy of ideals exists in market interactions which reflects the hierarchies among social groups, and norms of fairness are shaped by these hierarchies. While she does not directly discuss differences in perceptions, but if norms of fairness vary by social identities, this might be the mechanism underlying differential perceptions of self-worth. We believe our paper fills a gap 
in the economic literature on the relationship between social identity and perceptions of selfworth.

\section{Empirical Framework}

We use two principal methods to test for the relationships outlined above. We use censored regressions to estimate the effect of caste identity on perceptions about remunerative earnings. In order to examine whether institutional change can mediate the relationship between caste identity and perceptions, we use triple difference specifications explained below.

\subsection{Estimating the Effect of Caste Identity on Perceptions}

Consider the following economic model applied separately to each cross-section:

$$
y_{i}=\exp \left(\boldsymbol{x}_{i} \boldsymbol{\beta}+u_{i}\right)
$$

where $y_{i}$ is individual $i^{\prime} s$ perceived monthly earnings from self-employment that $\mathrm{s} / \mathrm{he}$ considers to be remunerative. $\boldsymbol{x}_{i}$ is a vector of observed characteristics, including caste. $u_{i}$ is the residual term. Taking logarithms,

$$
\ln y_{i}=\boldsymbol{x}_{i} \boldsymbol{\beta}+u_{i}
$$

In the EUS, $y_{i}$ (and therefore $\ln y_{i}$ ) is interval coded. The exact survey question about $y_{i}$ is as follows: "What amount of earnings (Rs. per month), would you regard as remunerative?" The response could be any one of the following six integer codes: (1) Less than or equal to Rs.1000; (2) Rs. 1001 to Rs. 1500; (3) Rs. 1501 to Rs. 2000; (4) Rs. 2001 to Rs. 2500; (5) Rs. 2501 to Rs. 3000; (6) More than Rs. 3000. We make the following identifying assumption,

$$
u_{i} \mid \boldsymbol{x}_{i}, \boldsymbol{r}_{i} \sim N\left(0, \sigma^{2}\right)
$$

where $\boldsymbol{r}_{i}$ is the individual's threshold value(s). ${ }^{8}$ The assumption implies that $u_{i}$ is independent of $\boldsymbol{x}_{i}$, and of $\boldsymbol{r}_{i}$. We therefore use Maximum Likelihood estimation to obtain consistent estimators of $\boldsymbol{\beta}$ and $\sigma^{2}$. ${ }^{9}$

\footnotetext{
${ }^{8}$ For example if $i$ chose (2) as their response code, then $\boldsymbol{r}_{i}$ is $(1001,1500)$.

${ }^{9}$ In order to separately identify $\boldsymbol{\beta}$ and $\sigma^{2}, \boldsymbol{r}_{i}$ should not be perfectly related to $\boldsymbol{x}_{i}$ (Wooldridge 2010). In our data thresholds vary across individuals and are not systematically related to their characteristics. Therefore, this condition is satisfied.
} 
The effect on perceptions of a particular characteristic, say $x_{k}$, is given by the semielasticity of mean perceived earnings, $E(y \mid x)$, with respect to $x_{k}$. Let this be denoted by $\theta_{k}$. When $u$ is independent of $\boldsymbol{x}$ (as we have assumed), it can be shown that $\theta_{k}=\beta_{k}$ (see Appendix A.1 for proof). For a categorical variable such as caste, the exact percentage change in mean perception between a specified caste group and the omitted group (upper caste in this paper) is given by $\exp \left(\beta_{j}-1\right) * 100$, where $\beta_{j}$ is the coefficient attached to the binary variable for the specified caste.

\subsubsection{Bounding the Pure Caste Effect: Choice of $x$}

We are interested in the pure effect of caste on perceptions after accounting for other characteristics that are correlated with caste and also have an independent effect on an individual's perception about remunerative earnings. We have data on the following characteristics which we categorize in four groups for reasons explained below: (A) gender, age and age squared, marital status, whether the individual is the head of household, household size, dependency ratio, ${ }^{10}$ area of residence (rural/urban), district of residence, survey month; (B) land owned by the household, educational attainment; (C) selfemployment category (single person enterprise, employer, or unpaid family worker), whether engaged in subsidiary activity, industry and occupation of employment; (D) household's monthly consumption expenditure (proxy for household income).

Characteristics listed in groups B, C, and D, are, at least to some extent, themselves determined by caste. ${ }^{11}$ Including them as part of $\boldsymbol{x}$ biases the pure caste effect (Angrist and Pischke 2009). In Appendix A.2 we sign the bias and show that inclusion of these variables would underestimate the pure caste effect. At the same time, excluding them would overestimate the effect due to the omitted variables bias. We therefore present results for four specifications of $\boldsymbol{x}, \mathrm{S} 1$ through S4, where each successive specification includes additional controls from (A) through (D). Thus, S1 which includes characteristics only in (A), provides an upper bound for the pure caste effect, while S4 which includes all four groups, provides a lower bound.

\subsection{Can Institutions Mitigate the Caste Effect?}

\footnotetext{
${ }^{10}$ Dependency ratio is defined as the fraction of all household members who are not employed.

${ }^{11}$ Deshpande (2011) and various papers in Thorat and Newman (2012) provide ample evidence of this.
} 
We use triple difference formulations to estimate the differential effects of MGNREGS and of the rise in power of a pro-Dalit political party, the BSP, on the perceptions of different caste groups.

\subsubsection{Identifying the Effect of MGNREGS}

Before outlining the methodology, it is useful to provide an introduction to the program in order to understand why this particular policy intervention is well-suited for our empirical question. MGNREGS is one of the largest public works programs in the world. It was first implemented in early 2006 in poorest districts of India, and by 2008 it had been rolled out throughout the country. It guarantees 100 days of wage-employment in a year to a rural household whose adult members are willing to do unskilled manual work at state-level statutory minimum wages. Dutta et al. (2012), and Liu and Barrett (2013) find that it has been successful in targeting the poor, mainly because it offers physically demanding manual work at low wages that is not attractive to the non-poor. Both studies also find higher participation rates for lower-ranked caste groups, which is not surprising given that these groups tend to be over-represented among the poor.

Several studies have found that the MGNREGS pushed up rural wage rates for private casual work (Azam 2012, Berg et al. 2015), and this in turn led to welfare gains among the poor that extended beyond those received by program participants (Imbert and Papp 2015). Klonner and Oldiges (2014) find that the scheme smoothed consumption expenditure among SC-ST households. Given this backdrop, it is plausible that MGNREGS raised earnings expectations and adequacy norms among the poor, and especially among lower-caste households. Ex-ante, we expect it to have a greater effect on the perceptions of lower-castes such that their notion of what constitutes a remunerative income increases vis-à-vis the upper-castes.

In order to examine if MGNREGS had a greater influence on the perceptions of lower-castes, it is not credible to use a Difference-in-Differences (DID) specification over time (2004-5 as pre-MGNREGS and 2009-10 as post-), and between caste groups. DID relies on the assumption that during this period, besides the introduction of the scheme, there were no other events that differently affected the perceptions of various caste groups. For this to be true, we would have to rule out some obvious possibilities such as differential price inflation 
across caste groups because of differences in their consumption baskets. ${ }^{12}$ To address this concern, we estimate two different triple difference specifications explained below.

The first triple difference relies on the variability across states in the actual implementation of the scheme. Although MGNREGS is stipulated to be demand driven, studies have suggested that political factors and lack of administrative capacity at various levels have led to supply constraints in actual provision of employment (Dutta et al. 2012; Imbert and Papp 2015; Mukhopadhyay 2012). Dutta et al. (2012), and Liu and Barrett (2013) use EUS 2009-10 to rank states according to participation rates, and the severity of rationing. Based on these rankings we classify 27 Indian states into two groups: 14 states characterised by high participation and low rationing, and the rest. We call the 14 best performing states as Star states. ${ }^{13}$

If our hypotheses is true and MGNREGS does have a larger effect on the perception of lower-castes, then, for the most part, this should be coming from the Star states which experienced better implementation of the scheme. We therefore combine data from both years and estimate the following triple difference specification (we have separated out the caste variables from $\boldsymbol{x}$ and called the remaining vector $\boldsymbol{x}_{1}$ ):

$$
\begin{aligned}
& \ln y_{i}=\beta_{0}+x_{1 i} \beta_{1}+\gamma_{1} S T_{i}+\gamma_{2} S C_{i}+\gamma_{3} O B C_{i} \\
& +\gamma_{4}{\text { Year } 09_{i}}+\sum \gamma_{5}^{k} \text { District }_{i}^{k} \\
& +\gamma_{6} S T_{i} * Y_{\operatorname{ear} 09_{i}}+\gamma_{7} S C_{i} * \operatorname{Year}_{0} 9_{i}+\gamma_{8} O B C_{i} * \operatorname{Year}_{0} 9_{i} \\
& +\gamma_{9} S T_{i} * \operatorname{Star}_{i}+\gamma_{10} S C_{i} * \operatorname{Star}_{i}+\gamma_{11} O B C_{i} * \operatorname{Star}_{i} \\
& +\sum \gamma_{12}^{j}{\text { Year } 09_{i} * \text { State }_{i}^{j}}^{j} \\
& +\gamma_{13} S T_{i} * \text { Year09 }_{i} * \operatorname{Star}_{i}+\gamma_{14} S C_{i} * \text { Year } 09_{i} * \text { Star }_{i} \\
& +\gamma_{15} O B C_{i} * \operatorname{Year}_{0} 9_{i} * \operatorname{Star}_{i}+\varepsilon_{i}
\end{aligned}
$$

where $S T_{i}, S C_{i}$, and $O B C_{i}$, are the binary variables capturing the caste of individual $i$; Year $09_{i}$, stands for whether s/he is from survey year 2009-10; tar $_{i}$ for whether s/he

\footnotetext{
${ }^{12}$ Azam (2012), and Imbert and Papp (2015) use EUS data and adopt a DID strategy to study the effects of MGNREGS on wage rates. However, they use 2007-8 data (instead of 2009-10) to exploit the partial implementation of the scheme. We cannot use a similar strategy because the question on perceptions was not asked in 2007-8.

${ }^{13}$ The 14 Star states are Andhra Pradesh, Chattisgarh, Himachal Pradesh, Madhya Pradesh, Manipur, Meghalaya, Mizoram, Nagaland, Rajasthan, Sikkim, Tamil Nadu, Tripura, Uttarakhand and West Bengal.
} 
belongs to one of the Star states; and District ${ }_{i}^{k}$ and State $_{i}^{j}$ are sets of district and state controls. The effect of MGNREGS on average perception gap between SC and UC is given by $\exp \left(\gamma_{2}\right)\left[\exp \left(\gamma_{7}+\gamma_{10}+\gamma_{14}\right)-\exp \left(\gamma_{7}\right)-\exp \left(\gamma_{10}\right)+1\right] * 100$ (derived in Appendix A.3). Because we expect the change over time in the gap between SC and UC in the Star states to be larger than the same in the non-Star states, we expect this effect to be positive. The effect of MGNREGS on average perception gap between ST and UC (and between OBC and UC) can be similarly estimated.

The second triple difference exploits the variation in exposure of districts to the scheme. MGNREGS was rolled out in a phased manner and was first implemented in poorer districts within each state (Imbert and Papp 2015). The districts that had the scheme earlier are called Phase I and II districts, and the rest Phase III. We expect the MGNREGS to have a greater impact on individuals residing in Phase I and II districts than those residing in Phase III as the former were exposed to the scheme for a longer duration. Based on this we estimate a triple difference specification similar to Equation (4), wherein Star $_{i}$ is replaced by Phase $12_{i}$, the latter captures whether $i$ resides in a Phase I or Phase II district.

We should note that non-Star states and Phase III districts are not pure controls in the sense that they were exposed to the scheme, albeit to a lesser extent. For this reason our estimates are to be viewed as lower bounds.

\subsubsection{Identifying the Effect of Change in Ruling Party}

Next we examine whether the coming to power of pro-Dalit BSP at the state level alters perceptions of Dalits such that they begin to expect larger amounts to be remunerative. We do so by looking at UP, the most populous state in India, where SC constituted 15 percent of the population in 2009-10. In UP, in 2004-5 the Mulayam Singh-led SP was in power (in the 2nd year of its term), and in 2009-10 it was Mayawati's BSP (in the 3rd year of its term). If we were to use data only from UP and estimate a DID specification (between the two years and across caste groups), then we would capture both the effect of a change in ruling party as well as the effect of other events such as the introduction of MGNREGS. To separate out the political representation effect, we estimate a triple difference using the adjacent state of Madhya Pradesh (MP). In MP the political party in power, viz., the Bhartiya Janata Party (BJP), did not change across the two years and therefore it constitutes a valid control state. However, we know that the implementation of MGNREGS was better in MP compared to UP: MP is one of our Star states while UP is not. By using MP as the control state we are 
being conservative about the influence of a pro-Dalit political party coming to power on Dalit perceptions. The triple difference specification used to identify the pro-Dalit ruling party effect is similar to Equation (4), where we replace $S t a r_{i}$ by $U P_{i}$, where $U P_{i}$ stands for whether $i$ belongs to UP. The conservative estimate of the effect of a shift to a pro-Dalit party is given by an expression similar to that derived for the MGNREGS effect.

\section{Data and Descriptive Statistics: Characterizing the Fully Self-Employed}

\subsection{Data}

We use data from the 61st and the 66th rounds of the EUS of the NSS pertaining to the years 2004-5 and 2009-10, respectively. These are repeated cross-sections and are representative both at the all-India and the state levels. The EUS rounds have been extensively used to study wage earners in India. However, in spite of the self-employed constituting about 50 percent of the labor force, there is very little empirical work on studying them. ${ }^{14}$ One reason is that unlike income data for wage earners, EUS does not record actual earnings from self-employment. In a small section of the questionnaire, and only in these two rounds, it only asks the self-employed whether they consider their current earnings to be remunerative, and also collects interval coded data on perceived remunerative earnings.

Possibly because this is a very small section in an otherwise detailed survey, this part of the NSS questionnaire has not been used extensively by researchers. Ours is the first paper to use this limited data for the self-employed to examine both their perceptions and actual earnings, and how this varies by social identity, specifically caste. The only other study to report limited statistics from this section is World Bank (2011), which reports that 40 percent of rural men and 80 percent of rural women found an income of less than Rs. 2000 to be "remuneration enough" (p.132). While the study does not comment on the gender differences in perception of remuneration, this limited statistic - that a larger proportion of women than men find a given level of earnings remunerative - is entirely consistent with our central hypothesis.

\footnotetext{
${ }^{14}$ A few recent exceptions are Deshpande and Sharma 2013 and 2016, and Vanneman and Dubey 2013. These papers use the India Human Development Survey (IHDS) and the MSME (Micro, Small and Medium Enterprises) Census data to study earnings from self-employment in India.
} 
We consider individuals in the working age population (between the ages 18 to 60 years), who are self-employed. ${ }^{15}$ This group is further refined to identify the set of 'fully selfemployed' individuals (FSE, hereafter), defined as those who are employed full-time, have worked regularly in the year preceding the survey, and have had not a single month without work. We impose this restriction in order to focus on a relatively homogenous population characterised by stable employment. ${ }^{16}$ Our analysis sample consists of 58,637 and 39,706 FSE individuals in 2004-5 and 2009-10, respectively, who represent, roughly 25 percent of the Indian labor force in both years.

The overwhelming majority of FSE are either own account workers (62 and 67 percent in 2004-5 and 2009-10, respectively) or unpaid family workers (35 and 30 percent in 2004-5 and 2009-10, respectively). Only a small share are employers (about 3 percent in both years). Thus, the discussion that follows is mostly about self-employed persons either operating single-person enterprises, or informally engaged in their family-owned establishments. It is not so much about persons running big businesses that employ other workers. This context needs to be kept in mind when assessing the amounts that are perceived as being adequately remunerative. In 2004-5 and 2009-10, 27 and 23 percent, respectively, of FSE were women. Roughly, 75 percent lived in rural areas. The educational attainment of FSE improved over the years: The share with no schooling declined from 36 to 26 percent, while those with secondary (Grade 10) or higher education increased from 24 to 32 percent. Majority (57 and 52 percent, in 2004-5 and 2009-10, respectively) were employed in primary industries such as agriculture, forestry, fishing and mining.

In 2009-10, 7 percent of FSE were ST, 12 percent SC, 47 percent OBC, and 34 percent the residual UC category. The caste distribution was very similar in 2004-5.

\subsection{Differences in Characteristics across Caste Groups}

Table 1 presents the distribution of characteristics across caste groups for the FSE population. We discuss characteristics for 2009-10, and note that similar patterns were seen in 2004-5. Female participation was highest for ST (36 percent) and lowest for UC (16 percent); for SCs and OBCs it was in- between at 25 percent. Compared to UC, all other caste groups had lower dependency ratios. In particular, while the ratio was 0.47 for ST, it was

\footnotetext{
${ }^{15}$ The EUS records what it calls 'the usual principal activity' of each individual. This refers to the activity in which s/he spent the longest time in the year preceding the survey. We use this to identify the self-employed.

${ }^{16}$ In both years, around 50 percent of the self-employed are FSE.
} 
0.56 for UC. SCs and OBCs owned less land than UCs. Surprisingly, STs owned more land, perhaps because of their geographic concentration in hilly and forested parts of the country. While 94 percent of STs lived in rural areas, only 66 percent of UCs did so. For SCs and OBCs the corresponding figures were 79 and 75 percent, respectively. There is clear evidence that higher caste groups have better educational attainment. While 48 and 37 percent of STs and SCs had no schooling, these figures were lower at 29 and 14 percent for OBCs and UCs respectively. At the other end of the spectrum, while only 12 and 20 percent of STs and SCs had attained an education level of Secondary (Grade 10) or above, 27 and 48 percent of OBCs and UCs respectively had attained this level. Compared to UCs, a smaller share of other groups were employers, which is confirmed by other data sources such as IHDS that show greater business ownership by UCs. A higher share of STs, SCs and OBCs engaged in subsidiary work in addition to their full-time employment. Compared to the other three caste groups, STs are predominantly employed in agriculture and allied industries. In terms of occupational distribution, a larger share of UCs are in higher paying administrative or professional occupations. While 27 percent of UCs were in these occupations, the corresponding figure for ST is 7 percent, SC 14 percent, and OBC 18 percent. Finally, better living standards among UCs is reflected in their higher monthly consumption expenditure. The average monthly consumption expenditure for UC households was 1.7, 1.6 and 1.3 times that of ST, SC, and OBC households respectively. Thus, Table 1 reveals that caste groups differ significantly in their characteristics. When attributing differences in perceptions to caste identity, it is therefore important to account for the fact that a part of these differences may be due to differences in characteristics.

\subsection{Differences in Perceptions across Caste Groups}

Here we examine the main outcome variable of interest, namely, (self-reported) perceptions on earning amounts that are considered to be remunerative. ${ }^{17}$ Table 2 presents these perceptions across caste groups among the FSE population. Note that the money amounts used to define the earnings intervals remain the same across both EUS rounds.

\footnotetext{
${ }^{17}$ The EUS has only one question on caste, namely, documenting the caste identity of the household. This information is collected in the 'Household Characteristics' module at the start (Block 3) of the questionnaire. The response about perceived remunerative earnings is collected in a separate module (Block 7.1) towards the end of the questionnaire. It is therefore unlikely that the survey design of itself directs the respondent's focus towards his caste identity when he is replying to the question on perceived earnings. We therefore believe that an individual's response mainly reflects the subliminal influence of his caste and is not biased by the survey design.
} 
Given inflation over the five-year period, ${ }^{18}$ these amounts are not comparable across years in real terms. It is therefore not surprising that while in 2004-5 about 65 percent of the FSE report earnings less than Rs. 3000 per month to be remunerative, only 30 percent do so in 2009-10.

We find that amounts that constitute remunerative earnings vary significantly by caste. In 2004-5, 82 percent of ST, 71 of SC, 70 of OBC, and 54 of UC consider monthly earnings less than Rs. 3000 per month as being remunerative. In 2009-10, 45 percent of ST, 37 of SC, 34 of OBC, and 19 of UC consider this amount to be remunerative. ${ }^{19}$ Thus, compared to upper castes, lower caste groups - SC, ST and OBCs perceive lower amounts as being remunerative. As mentioned earlier, these differences in perceptions across caste groups could partly be due to differences in their characteristics. For example, ignoring for a moment that caste may itself determine educational attainment, lower caste individuals may recognize that their earning capacity is constrained by their lower educational attainment and may therefore consider lower amounts as being remunerative. However, as outlined above, we are interested in estimating the 'pure' caste effect, i.e. the effect of social identity after these characteristics have been accounted for.

\section{Main Results: Caste Identity and Perceptions about Remunerative Earnings}

We first show how an individual's caste identity affects their perceptions about remunerative earnings. This is followed by the effects of institutional change on perceptions of different caste groups.

\subsection{Effect of Caste Identity on Perceptions}

Table 3 presents the estimates of the semi-elasticity of mean perceived remunerative earnings with respect to caste. For each year, columns S1 through S4 show the results for the specifications with the same labels as discussed in section 3.1.1. As predicted, the caste effects decrease in magnitude as we move from S1 (the most parsimonious) to S4 (the full specification). Given the negative bias discussed in Appendix A.2, S4 provides the most conservative estimates. We discuss the results from this specification bearing in mind that

\footnotetext{
${ }^{18}$ The All-India Consumer Price Index (CPI) for rural labourers (base 1986/87=100) increased from 340 in 2004 to 493.5 in 2009, an increase of 45 percent. The index numbers are obtained from the Labour Bureau, Government of India (source: http://labourbureau.nic.in/indtab.html accessed on June 22, 2015).

${ }^{19}$ We carry out a Pearson's chi-square test to examine whether amounts considered as remunerative earnings are independent of caste. The test does not support the hypothesis of independence.
} 
these are lower bounds. In 2004-5, the average amount perceived to be remunerative by STs was at least 7.3 percent lower than that perceived by UCs, and the corresponding figures for SC and OBC were 4.8 and 2.6 percent respectively. In 2009-10, ST perceptions were at least 9 percent lower than UC, and for SC and OBC they were 9.2 and 5.1 percent lower, respectively. Semi-elasticity estimates for gender and education are also along expected lines: Compared to men, women perceived lower earnings to be remunerative, and the amount considered remunerative increased with educational attainment.

The important conclusion is that there is clear evidence that caste identity matters in defining self-worth: after accounting for differences in other observed characteristics, groups that are lower in the caste hierarchy also consider smaller amounts to be remunerative.

\subsection{Evidence of Institutions Mitigating the Caste Effect}

In Tables 4A and 4B we present the effect of MGNREGS, and in Table 5, of the change in ruling party in UP. Each table shows results from estimating a triple difference formulation (Equation (4) or similar), wherein two specifications of $\boldsymbol{x}, \mathrm{S} 2$ and S4 (described in section 3.1.1) have been used. Recall that S2 does not control for employment characteristics and consumption expenditure (our proxy for income), while S4 includes the complete set of controls.

Here we explain why we estimate only two of the four specifications of $\boldsymbol{x}$.

Institutional change can affect caste specific perceptions either by directly affecting notions of adequacy (and without any change in economic realities), or they may first improve employment conditions and raise incomes which in turn may raise notions of adequacy. Of course, both these could also be happening simultaneously. While S2 captures the effects of both, S4 only captures the former as it controls for employment characteristics and income. Thus, S2 estimates what may be called the 'policy' effect of the institutional change (i.e. the total effect), while S4 controls for some plausible mechanisms through which the change may be operating and therefore gives a 'partial' effect. We compare estimates across the two specifications to remark on plausible mechanisms through which the effect may be operating, but focus on $\mathrm{S} 2$ to conclude whether a particular institutional change had an overall differential effect on perceptions of caste groups. Since we are using triple differences, our estimates would be biased only if the difference in changes over time in the perceptions of any two caste groups were different between control units (Non-star states, Phase III districts, and MP) and treatment units (Star states, Phase I and II districts and UP) in the absence of the 
institutional change. Unfortunately, EUS does not have data on perceptions for other years to test this empirically.

\subsubsection{MGNREGS Effect}

Table 4A shows the results for the Star versus Non-star specification. Looking at S2, there are no significant effects of MGNREGS. When we consider S4, we find that MGNREGS improved the perception of ST and OBC vis-à-vis UC in what they regard as remunerative earnings: For ST the improvement was 13.9 percentage points, and for OBC it was 8.3 percentage points, though the latter is significant only at the 10 percent level. That the program effect shows up in S4 but not in S2 is somewhat puzzling. We conjecture that the additional controls in S4 may be capturing different pre-program trends. Table 4B shows the results for the Phase I\&II versus Phase III specification. Looking at S2 we find that the scheme improved the perception of OBC vis-à-vis UC by 5.2 percentage points, and this effect is 5.6 percentage points when we control for economic outcomes in S4. Given that the magnitude of effects is similar across S1 and S4, we conclude that MGNREGS is operating by raising the adequacy norms among OBCs rather than by changing actual employment or income realities.

Given that our identification strategy underestimates the scheme's effect, we interpret the results in tables $4 \mathrm{~A}$ and $4 \mathrm{~B}$ as evidence to support that MGNREGS led to an unambiguous improvement in the relative perceptions of OBCs in what they regard as remunerative earnings.

\subsubsection{Pro-Dalit Ruling Party Effect}

Table 5 presents the results for the UP versus MP triple difference specification. Both S2 and S4 provide strong evidence that the change in ruling party in UP from SP to pro-Dalit BSP resulted in a significant relative improvement in the perceptions of SC vis-à-vis UC in what they consider as remunerative earnings. The magnitude of effect is large, 31.7 and 29.7 percentage points when we look at S2 and S4, respectively. ${ }^{20}$ Again, it appears that the shift in political party is influencing Dalit perceptions via a change in adequacy norms (perhaps due to a boost in Dalit pride), rather than a change in economic realities.

\section{Caste Identity and Actual Earnings}

\footnotetext{
${ }^{20} \mathrm{We}$ do not present the results for ST as UP does not have a sizable ST population: In 2009-10, their population share was 0.1 percent.
} 
We turn to what can be learned from the EUS about actual earnings. Recall that the EUS does not directly capture earnings from self-employment. However, in addition to the question on perceived remunerative earnings, it asks the following question: "Do you regard the current earning from self-employment as remunerative? (yes -1, no -2)" Table 6 shows how information about actual earnings can be deduced using the responses to these two questions. For example, if an individual says that $\mathrm{s} /$ he does not consider his current earnings as remunerative, and also that s/he considers an amount between Rs. 1001 and Rs. 1500 to be remunerative, then we can conclude that their actual earnings must be less than or equal to Rs. 1000. On the other hand, if s/he considers their current earnings as remunerative, and also considers an amount between Rs. 1001 and Rs. 1500 to be remunerative, then their actual earnings must be between Rs. 1001 and Rs. 1500. The only pair of responses from which nothing conclusive can be deduced is when an individual does not consider their current earnings as remunerative, and considers an amount more than Rs. 3000 to be remunerative.

Table 7 presents information on actual earnings deduced in the manner described above. As we can see, self-employment earnings of lower-castes is less than that of uppercastes: In 2009-10, the shares of ST, SC, OBC, and UC, earning less than Rs. 1000 per month were 6, 5.8, 3.6, and 2.3, percent respectively; while the shares earning greater than Rs. 3000 per month were $30.2,29.1,36.7$, and 46.8 respectively. Similar pattern is seen in 2004-5 as well.

\subsection{Effect of Caste Identity on Actual Earnings, 2004-5}

Here we account for observable characteristics and estimate the effect of caste identity on actual earnings. Note that in 2004-5 and 2009-10, for 15 and 31 percent of the sample, respectively, we could not deduce anything about their actual earnings (see Table 7). Given the large share of missing earnings for 2009-10, we only analyse data for 2004-5. Once again we use a censored regression model similar to the one discussed in section 3.1. Equations (1), (2) and (3) apply, but $y_{i}$ now stands for actual earnings. The results are summarized in Table $8 .{ }^{21}$ We find that actual earnings vary by caste such that lower-castes earned smaller amounts compared to upper-castes even after controlling for observable characteristics. Using the most conservative estimates for the effect of caste on earnings (S3), in 2004-5, the average amount

\footnotetext{
${ }^{21}$ We do not estimate specification S4 that controls for monthly consumption expenditure (mce) because now the dependent variable is monthly earnings and mce is a proxy for it.
} 
earned by ST was 18 percent lower than that earned by UC, and the corresponding figures for $\mathrm{SC}$ and $\mathrm{OBC}$ were 16.8 and 8 percent, respectively.

One might be concerned that missing earnings data might introduce some bias. Note that data on earnings is missing for those individuals who do not consider their current earnings to be remunerative, and who choose the highest category (more than Rs. 3000) as what they consider as remunerative earnings. These are presumably the more ambitious individuals who are perhaps more likely to have higher actual earnings, all else being the same. This, combined with the fact that the percentages of missing are either lower (for ST and $\mathrm{OBC}$ ) or comparable (for SC) vis-à-vis UC (see Table 7), we expect that missing earnings result in an underestimation of the caste effect.

\subsection{Effect of Caste Identity on Consumption Expenditure}

Given that we have used monthly consumption expenditure as a proxy for income, in this section we examine whether monthly per capita consumption expenditure is affected by one's caste identity. Table 9 presents the results for Ordinary Least Squares (OLS) regressions where (logarithm) monthly per capita consumption expenditure is regressed on three sets of control variables, S1, S2, and S3 as described in Section 3.1.1. ${ }^{22}$ Using our most conservative estimate (S3), we find that lower caste individuals consume smaller amounts: In 2004-5, the per capita consumption expenditure of ST was 24 percent lower than that for UC, while for SC and OBC it was 20.3 and 10.9 percent lower, respectively. In 2009-10 for ST it was 20.5 percent lower, while for SC and $\mathrm{OBC}$ it was 15.5 and 8.9 percent lower, respectively.

\subsection{Effect of Institutions on Consumption Expenditure}

Here we examine whether MGNREGS or the change in ruling party in UP had differential impacts on the consumption expenditure of different caste groups. Tables 10 summarizes the results from triple difference regressions (similar to Equation (4)), where the dependent variable is (logarithm) monthly per capita consumption expenditure. Results for S2 and S3 are shown. ${ }^{23}$ There is weak evidence that MGNREGS increased the consumption expenditure of SC vis-à-vis UC: For the Phase I\&II versus Phase III specification, S2 and S3

\footnotetext{
${ }^{22}$ An individual's monthly per capita consumption expenditure is obtained by dividing his household's monthly consumption expenditure by household size. Therefore, household size is not included as an additional control.

${ }^{23}$ As discussed in Section 5.2, S2 captures the policy/total effect of institutional change, while S3 controls for employment characteristics and captures the partial effect.
} 
reveal that SC perceptions vis-à-vis UC improved by 6.2 and 6.1 percentage points, respectively, however these are significant only at the 10 percent level. There is no evidence that MGNREGS has any differential effect on the consumption expenditure of ST and OBC vis-à-vis UC. This is consistent with our finding for OBCs in Section 5.2.1 and Table 4B, where we concluded that the effect of MGNREGS on perceptions must be operating via adequacy norms rather than a change in employment characteristics or actual income.

Finally, the change in ruling party in UP from SP to BSP did not have any differential effect on the consumption expenditure of SC or OBC vis-à-vis UC, again a finding consistent with our discussion in Section 5.2.2.

\section{Discussion}

Since we are using the specific question about perception of income from selfemployment as being remunerative as a proxy for self-worth, a question that arises is what exactly does the word "remunerative" convey to the respondent? Is it a valid proxy to use for self-worth? We accessed the NSS question in English. However, the actual survey was administered in a different language in each state. Our own lack of fluency with the 22 official languages of India prevents us from understanding the exact word used in each language. However, we looked up the Hindi survey instrument (which we understand perfectly) since Hindi is the most widely spoken language in India. The exact question in Hindi $^{24}$ connotes the notion of appropriate earnings, given effort (and remunerative is not used as sufficient or adequate). We believe this interpretation of remunerative fits in perfectly with the notion of self-worth and thus constitutes a valid proxy for our purpose.

Perceptions can have 'real' consequences. Social psychologists have documented the causal nature of the impact of perceived racial discrimination on African American psychological well-being (Sellers and Shelton, 2003). We conjecture about the relationship between perceptions of self-worth, as captured through their perceptions about the adequacy of remuneration, and actual earnings. We find that caste gaps in perceptions are smaller than those in actual earnings. This begs another question: what might be the direction of the relationship between perceptions and actual earnings? Is it the case that perceptions affect actual earnings? This would be true if lower-placed groups have lower expectations, which then becomes a self-fulfilling prophecy? It is difficult to answer this question based on the

24 "Kya aap swa-rozgar se aay ko upayukt parishramik maante hain?" 
data at our disposal; however, it cannot be ruled out. Causality between the two could run the other way around too. Actual earnings might impact perceptions: lower-ranked groups internalise existing disparities as "normal" and/ or expect discriminatory treatment, and thus, have lower perceptions. This channel has been discussed in Section 2. Deshpande and Sharma (2016) show discriminatory gaps in actual earnings for small-scale business: a part of the earnings gap remains even after controlling for observable characteristics. If lower-caste groups are aware of the discrimination they face, their notions of amounts that constitute remunerative earnings are likely to be shaped by the ground realities. This channel of the relationship between perceptions and actual earnings appears highly likely. Theoretically, there is also a third possibility, viz., that perceptions and actual earnings are independent. Based on the evidence so far, that appears unlikely.

Our results also have indirect bearing on the debate over caste-based affirmative action policies in India that are implemented through quotas in public employment. Arguments in favour of abolition of quotas question the extent to which caste identity is salient in contemporary India and wonder whether the existence of quotas solidifies caste identities, which if left untouched, might be losing their hold. Our paper shows the pervasive and pernicious effects of caste identity on self-worth in the sphere of self-employment which is completely outside the purview of quotas (and thus, the salience of caste identity could not be explained by quotas). Hence, quotas should be seen as a remedy for underlying casteism, and not its cause.

\section{Conclusion}

Using data from two rounds of the EUS of NSS for 2004-5 and 2009-10, we investigate the relationship between social identity, specifically caste identity in India, and perceptions of self-worth as measured by the amounts that individuals consider remunerative from self-employment. We also investigate if institutional change (e.g. a policy intervention or change in the ruling party in power) mitigates this relationship. Finally we analyse the relationship between caste identity and actual earnings (not just perceptions) and how institutions might affect it. Our main finding is that caste identity in contemporary India does shape self-worth. We find that controlling for other characteristics, among the fully selfemployed, lower-ranked groups perceive lower amounts as being remunerative. Further, institutional factors affect these self-perceptions but in more nuanced ways than our ex-ante beliefs. Specifically, MGNREGS boosts OBCs' perceptions of remunerative earnings vis-a- 
vis UC perceptions and a pro-Dalit ruling party (BSP in Uttar Pradesh) boosts Dalit perceptions of remunerative earnings vis-a-vis upper-caste perceptions. We are also able to conclude about the mechanisms through which institutions might be operating. In both cases, we find that the institutional change directly influences adequacy norms rather than changing economic realities (such as employment characteristics and income).

We use a unique method to assess actual earnings in the absence of data on actual earnings. Confirming other studies, we find that caste Identity affects actual earnings from self-employment. However, consistent with our earlier conclusion, we do not find that MGNREGS or the change in ruling party in UP had differential effects on the consumption expenditure (our proxy for actual earnings) of caste groups. We find that perception gaps are smaller than actual earnings gaps. Our data do not allow us to test for causality between the two, so we can only speculate about whether perception gaps cause gaps in actual earnings or the other way around. That exploration could be the matter of future research.

\section{References:}

Akerlof, George A., and Rachel E. Kranton. 2011. Identity Economics: How Our Identities Shape Our Work, Wages, and Well-Being. Princeton: Princeton University Press.

Angrist, J. D, and Jörn-Steffen Pischke. 2009. Mostly Harmless Econometrics: An Empiricist's Companion. Princeton: Princeton University Press.

Azam, M. 2012. "The Impact of Indian Job Guarantee Scheme on Labor Market Outcomes: Evidence from a Natural Experiment.” IZA Discussion Paper 6548.

Berg, Erlend, Sambit Bhattacharyya, D Rajasekhar, and R Manjula. 2015. "Can Public Works Increase Equilibrium Wages? Evidence from India's National Rural Employment Guarantee.” http://www.erlendberg.info/agwages.pdf. Accessed on June 1, 2016.

Berkowitz, Leonard, Colin Fraser, Peter F. Treasure, and Susan Cochran. 1987. "Pay, equity, job gratifications, and comparisons in pay satisfaction." Journal of Applied Psychology, 72(4): 544-551.

Bourdieu, Pierre. 1984. Distinction: A Social Critique of the Judgement of Taste. Translated by Richard Nice. Cambridge, Massachusetts: Harvard University Press

Bros, Catherine. 2014. "The Burden of Caste on Social Identity in India". The Journal of Development Studies 50(10): 1411-1429. 
Charles, Aurelie. 2013. "Hierarchy of Ideals in Market Interactions: An Application to the Labor Market”. Centre for Development Studies, University of Bath Working Paper 779.

Clayton, S., A. L. Garcia, and F. J. Crosby. 2010. "Women in the Workplace:

Acknowledging Difference in Experience and Policy" in Handbook of Diversity in Feminist Psychology, edited by H. Landrine, and N. F. Russo, 559-584. New York: Springer Publishing Company LLC.

Deshpande, Ashwini. 2011. The Grammar of Caste: Economic Discrimination in Contemporary India. Oxford University Press.

Deshpande, Ashwini and Katherine Newman. 2007. "Where the Path Leads: The Role of Caste in Post-University Employment Expectations." Economic and Political Weekly 42(41): 4133-4140.

Deshpande, Ashwini and Smriti Sharma. 2013. "Entrepreneurship or Survival? Caste and Gender of Small Business in India." Economic and Political Weekly 48(28): 38-49.

Deshpande, Ashwini and Smriti Sharma. 2016. "Disadvantage and Discrimination in SelfEmployment: Caste Gaps in Earnings in Indian Small Businesses.” Small Business Economics: An Entrepreneurship Journal 46(2): 325-346.

Dutta, Puja, Rinku Murgai, Martin Ravallion, and Dominique van de Walle. 2012. "Does India's Employment Guarantee Scheme Guarantee Employment?” Economic and Political Weekly 47(16): 55-64.

Fiske, Susan T., A.J. Cuddy, P. Glick, and J. Xu (2002). 'A Model of (Often Mixed) Stereotype Content: Competence and Warmth Respectively Follow from Perceived Status and Competition'. Journal of Personality and Social Psychology, 82(6): 878-902.

Foucault, Michel. 1982. “The Subject and Power.” Critical Inquiry 8(4): 777-795

Foucault, Michel. 1994. "The Order of Things: An Archaeology of the Human Sciences." A translation of, "Les Mots et les choses," 1966. Vintage Books Edition.

Goffman, E. 1963. Stigma: Notes on the management of spoiled identity. Prentice-Hall: Englewood Cliffs, NJ.

Hoff, Karla, and Priyanka Pandey. 2006. "Discrimination, Social Identities and Durable Inequalities, American Economic Review, 96(2), 206-211 
Hogue, Mary, and Janice D. Yoder. 2003. "The role of status in producing depressed entitlement in women's and men's pay allocations." Psychology of Women Quarterly 27(4): 330-337. 10.1111/1471-6402.00113.

Imbert, C, and J Papp. 2015. "Labor Market Effects of Social Programs: Evidence from India's Employment Guarantee". American Economic Journal: Applied Economics 7(2):233263.

Jaspal, Rusi. 2011. "Caste, Social Stigma and Identity Processes”. Psychology and Developing Societies 23(1): 27-62. 10.1177/097133361002300102.

Keavny, Timothy J., and Edward J. Inderrieden. 2000. “Gender Differences In Pay Satisfaction And Pay Expectations”. Journal of Managerial Issues 12(3): 363-379.

Klonner, Stefan, and Christian Oldiges. 2014. "Safety Net for India's poor or Waste of Public Funds? Poverty and Welfare in the Wake of the World's Largest Job Guarantee Program.” University of Heidelberg, Department of Economics Discussion Paper Series No. 564.

Liu, Yanyan, and Christopher B Barrett. 2013. "Heterogeneous Pro-Poor Targeting in the National Rural Employment Guarantee Scheme.” Economic and Political Weekly vol XLVIII (10): 46-53.

Major, Brenda, and Laurie T. O'Brien. 2005. "The social psychology of stigma." Annual Review of Psychology 56: 393-421. 10.1146/annurev.psych.56.091103.070137.

Major, Brenda and Mark Zanna. 1994. "From social inequality to personal entitlement: The role of social comparisons, legitimacy appraisals, and group membership". Advances in Experimental Social Psychology 26: 293-355. 10.1016/s0065-2601(08)60156-2

Mukhopadhyay, A. 2012. "The political economy of implementing the National Rural Guarantee Scheme in India.” Effective States and Inclusive Development (ESID) Working Paper 15.

Navsarjan Trust, with the Robert F Kennedy Centre for Human Rights (2010):

"Understanding Untouchability: A Comprehensive Study of Practices and Conditions in 1589 Villages", Washington D C.

Rubin, D. 1974. "Estimating Causal Effects of Treatments in Randomized and Nonrandomized Studies.” Journal of Educational Psychology 66(5): 688-701. 
Sellers, Robert M., Nikeea Copeland-Linder, Pamela P. Martin, and RL'Heureux Lewis. 2006. "Racial identity matters: The relationship between racial discrimination and psychological functioning in African American adolescents." Journal of Research on Adolescence 16(2): 187-216.

Sellers, Robert M., and J. Nicole Shelton. 2003. "The role of racial identity in perceived racial discrimination." Journal of personality and social psychology 84(5): 1079-1092.

Shah, Ghanshyam, Harsh Mander, S. K. Thorat, Satish Deshpande, and Amita Baviskar. 2006. Untouchability in Rural India. New Delhi: Sage.

Steele, Claude M. and Joshua Aronson. 1995. "Stereotype Threat and Intellectual Task Performance of African Americans.' Journal of Personality and Social Psychology 69:797811.

Tajfel, H., and J.C. Turner. 1986. "The social identity theory of intergroup conflict". In Psychology of intergroup relations edited by S. Worchel, and W.G. Austin, 7-24. Chicago: Nelson-Hall.

Thorat, Sukhadeo, and Katherine S. Neuman. 2012. Blocked by caste: economic discrimination in modern India. Oxford: Oxford University Press.

Vanneman, Reeve, and Amaresh Dubey. 2013. "Horizontal and Vertical Inequalities in India." In Income Inequality: Economic Disparities and the Middle Class in Affluent Countries, edited by J. C. Gornick and M. Jantti, 439-458. Stanford: Stanford University Press.

Wooldridge, J. M. 2010. Econometric Analysis of Cross Section and Panel Data. Cambridge, Massachusetts: The MIT Press.

World Bank. 2011. Perspectives on poverty in India: Stylized Facts from Survey Data. Washington, DC: World Bank. 10.1596/978-0-8213-8689-7. 
Table 1: Descriptive Statistics (Mean/ Share) by Caste, Fully Self-Employed

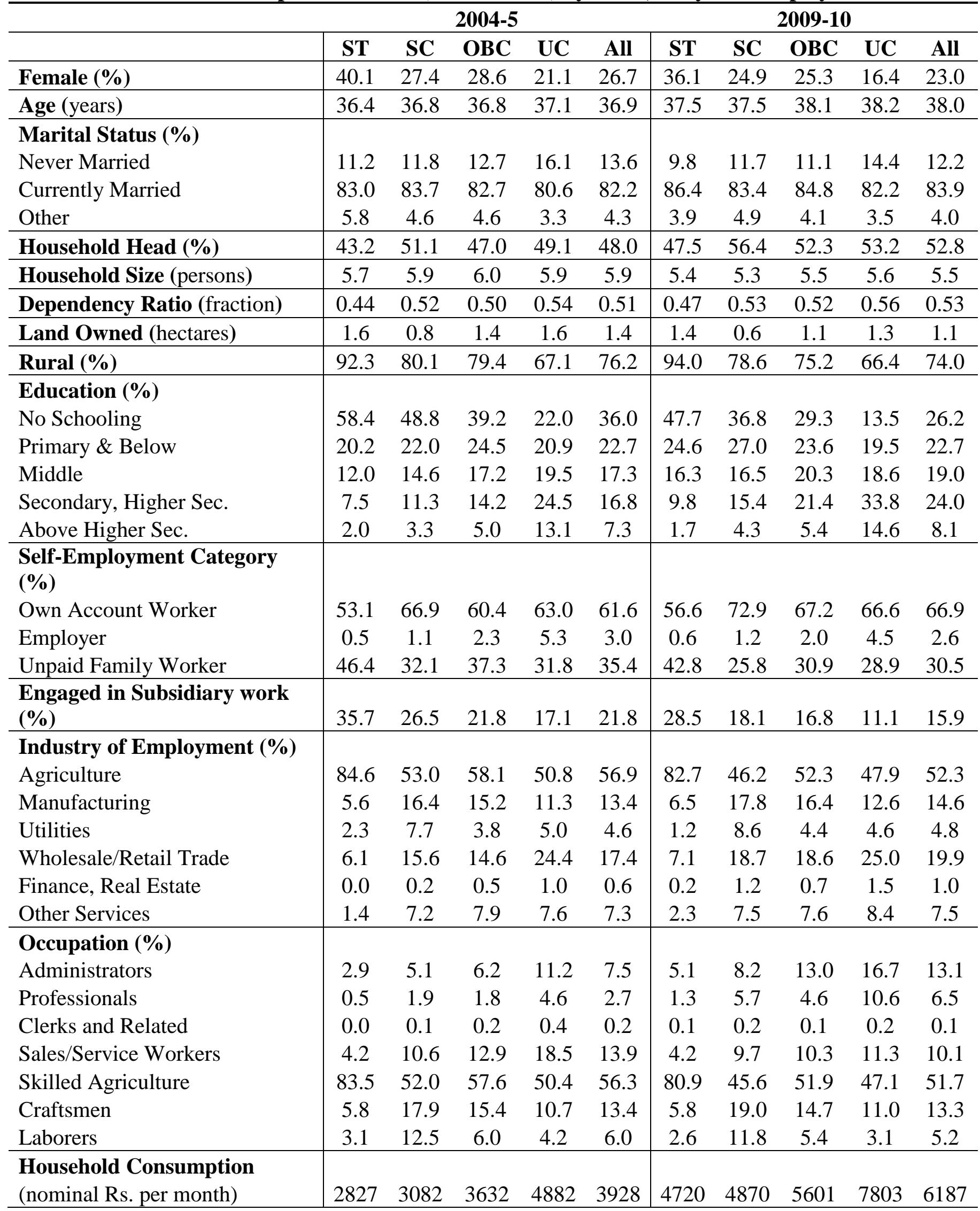


Table 2: Amounts Perceived as Remunerative Earnings by Caste, Fully Self-Employed

\begin{tabular}{l|ccccc|ccccc}
\hline & \multicolumn{5}{|c|}{$\mathbf{2 0 0 4 - 5}$ (Shares in \%) } & \multicolumn{5}{c}{ 2009-10 (Shares in \%) } \\
\hline & ST & SC & OBC & UC & All & ST & SC & OBC & UC & All \\
\hline Less than equal to Rs. & & & & & & & & & & \\
1000 & 21.9 & 11.8 & 11.8 & 6.0 & 10.5 & 4.3 & 4.7 & 2.6 & 1.8 & 2.7 \\
Rs. 1001 to Rs. 1500 & 20.0 & 18.3 & 16.2 & 12.0 & 15.4 & 8.4 & 4.0 & 5.6 & 2.3 & 4.5 \\
Rs. 1501 to Rs. 2000 & 16.5 & 16.1 & 16.3 & 13.7 & 15.4 & 15.5 & 9.7 & 8.3 & 4.3 & 7.6 \\
Rs. 2001 to Rs. 2500 & 11.0 & 11.5 & 11.4 & 10.0 & 10.9 & 4.8 & 5.6 & 6.7 & 3.6 & 5.4 \\
Rs. 2501 to Rs. 3000 & 12.4 & 13.7 & 13.9 & 12.0 & 13.1 & 12.3 & 12.9 & 10.8 & 7.3 & 10.0 \\
More than Rs. 3000 & 18.2 & 28.6 & 30.4 & 46.3 & 34.7 & 54.6 & 63.1 & 66.2 & 80.7 & 69.9 \\
\hline Total & 100.0 & 100.0 & 100.0 & 100.0 & 100.0 & 100.0 & 100.0 & 100.0 & 100.0 & 100.0 \\
\hline
\end{tabular}

Note: Amounts reported in the first column are in Rs. per month 
Table 3: Semi-Elasticity of Mean Perceived Remunerative Earnings w.r.t. various Characteristics

\begin{tabular}{|c|c|c|c|c|c|c|c|c|}
\hline & \multicolumn{4}{|c|}{ 2004-5 } & \multicolumn{4}{|c|}{ 2009-10 } \\
\hline & S1 & S2 & S3 & S4 & S1 & S2 & S3 & S4 \\
\hline \multicolumn{9}{|l|}{ Caste (Omitted UC) } \\
\hline ST & $\begin{array}{l}-19.07 \\
(1.44)\end{array}$ & $\begin{array}{c}-12.58 \\
(1.57)\end{array}$ & $\begin{array}{l}-10.7 \\
(1.60)\end{array}$ & $\begin{array}{l}-7.27 \\
(1.65)\end{array}$ & $\begin{array}{c}17.17 \\
(2.47) \\
-\end{array}$ & $\begin{array}{l}-12.87 \\
(2.68)\end{array}$ & $\begin{array}{c}-11.6 \\
(2.73) \\
-\end{array}$ & $\begin{array}{l}-8.99 \\
(2.78)\end{array}$ \\
\hline $\mathrm{SC}$ & $\begin{array}{r}-16.27 \\
(0.99)\end{array}$ & $\begin{array}{l}-9.49 \\
(1.10)\end{array}$ & $\begin{array}{l}-7.75 \\
(1.12)\end{array}$ & $\begin{array}{l}-4.77 \\
(1.15)\end{array}$ & $\begin{array}{l}17.28 \\
(1.94)\end{array}$ & $\begin{array}{r}-11.73 \\
(2.16)\end{array}$ & $\begin{array}{l}11.21 \\
(2.14)\end{array}$ & $\begin{array}{l}-9.18 \\
(2.19)\end{array}$ \\
\hline $\mathrm{OBC}$ & $\begin{array}{c}-10.3 \\
(0.79) \\
\end{array}$ & $\begin{array}{c}-5.5 \\
(0.86)\end{array}$ & $\begin{array}{c}-4.42 \\
(0.86) \\
\end{array}$ & $\begin{array}{l}-2.57 \\
(0.87) \\
\end{array}$ & $\begin{array}{c}-9.9 \\
(1.76) \\
\end{array}$ & $\begin{array}{l}-6.48 \\
(1.89) \\
\end{array}$ & $\begin{array}{c}-6.44 \\
(1.88) \\
\end{array}$ & $\begin{array}{c}-5.06 \\
(1.89) \\
\end{array}$ \\
\hline Female & $\begin{array}{r}-25.78 \\
(0.72) \\
\end{array}$ & $\begin{array}{r}-19.47 \\
(0.82) \\
\end{array}$ & $\begin{array}{l}-19.7 \\
(0.83) \\
\end{array}$ & $\begin{array}{r}-19.44 \\
(0.82) \\
\end{array}$ & $\begin{array}{l}-26.5 \\
(1.61) \\
\end{array}$ & $\begin{array}{r}-21.78 \\
(1.82) \\
\end{array}$ & $\begin{array}{c}- \\
21.35 \\
(1.84) \\
\end{array}$ & $\begin{array}{c}- \\
21.57 \\
(1.83) \\
\end{array}$ \\
\hline $\begin{array}{l}\text { Education (Omitted No } \\
\text { Schooling) }\end{array}$ & No & & & & No & & & \\
\hline Primary and Below & & $\begin{array}{c}5.25 \\
(0.98)\end{array}$ & $\begin{array}{c}4.46 \\
(0.97)\end{array}$ & $\begin{array}{c}3.3 \\
(0.95)\end{array}$ & & $\begin{array}{c}2.02 \\
(2.09)\end{array}$ & $\begin{array}{l}1.56 \\
(2.09)\end{array}$ & $\begin{array}{c}1.21 \\
(2.06)\end{array}$ \\
\hline Middle & & $\begin{array}{l}13.88 \\
(1.23)\end{array}$ & $\begin{array}{l}11.96 \\
(1.21)\end{array}$ & $\begin{array}{c}9.11 \\
(1.17)\end{array}$ & & $\begin{array}{c}9.09 \\
(2.55)\end{array}$ & $\begin{array}{c}7.74 \\
(2.53)\end{array}$ & $\begin{array}{c}6.09 \\
(2.49)\end{array}$ \\
\hline Secondary and Higher Sec. & & $\begin{array}{l}23.46 \\
(1.43)\end{array}$ & $\begin{array}{l}19.48 \\
(1.39)\end{array}$ & $\begin{array}{c}14.2 \\
(1.33)\end{array}$ & & $\begin{array}{c}14.9 \\
(2.82)\end{array}$ & $\begin{array}{l}13.29 \\
(2.79)\end{array}$ & $\begin{array}{l}10.42 \\
(2.74)\end{array}$ \\
\hline Above Higher Secondary & & $\begin{array}{l}45.32 \\
(2.58) \\
\end{array}$ & $\begin{array}{r}36.76 \\
(2.51) \\
\end{array}$ & $\begin{array}{l}24.68 \\
(2.31) \\
\end{array}$ & & $\begin{array}{r}36.2 \\
(5.05) \\
\end{array}$ & $\begin{array}{r}32.5 \\
(5.11) \\
\end{array}$ & $\begin{array}{l}22.07 \\
(4.74) \\
\end{array}$ \\
\hline Remaining Group A controls ${ }^{1}$ & Yes & Yes & Yes & Yes & Yes & Yes & Yes & Yes \\
\hline Remaining Group B control $^{2}$ & No & Yes & Yes & Yes & No & Yes & Yes & Yes \\
\hline Group $\mathbf{C}$ controls ${ }^{3}$ & No & No & Yes & Yes & No & No & Yes & Yes \\
\hline $\begin{array}{l}\text { Group D control }{ }^{4} \\
\text { Number of Observations }\end{array}$ & $\begin{array}{c}\text { No } \\
57716\end{array}$ & $\begin{array}{c}\text { No } \\
53838\end{array}$ & $\begin{array}{l}\text { No } \\
53719\end{array}$ & $\begin{array}{c}\text { Yes } \\
53698\end{array}$ & $\begin{array}{c}\text { No } \\
39093\end{array}$ & $\begin{array}{c}\text { No } \\
36593\end{array}$ & $\begin{array}{c}\text { No } \\
36481\end{array}$ & $\begin{array}{c}\text { Yes } \\
36481\end{array}$ \\
\hline
\end{tabular}

1. Includes age, age squared, marital status, whether head of the household, household size, dependency ratio, area of residence (rural/urban), district of residence, and survey month.

2. Includes land owned.

3. Includes self-employment category, whether engaged in subsidiary activity, industry and occupation of employment.

4. Includes monthly consumption expenditure of the household.

Standard errors in parentheses, clustered at the village (rural areas) or block (urban areas). 
Table 4A: Differential Effects of MGNREGS on Perceptions

(Star versus Non-Star)

\begin{tabular}{|c|c|c|c|c|c|}
\hline & \multicolumn{2}{|c|}{ Star States } & \multicolumn{2}{|c|}{ Non-Star States } & \multirow[b]{2}{*}{$\begin{array}{c}\text { Impact } \\
\text { Estimate }\end{array}$} \\
\hline & 2009-10 & 2004-5 & 2009-10 & 2004-5 & \\
\hline \multicolumn{6}{|c|}{$\begin{array}{c}\text { S2: Not Controlling for Employment Characteristics and Consumption } \\
\text { Expenditure } \\
(64840 \text { observations })\end{array}$} \\
\hline & \multicolumn{4}{|c|}{ (perception gap expressed as $\%$ of UC perception) } & $\begin{array}{c}\text { (percentage } \\
\text { points) }\end{array}$ \\
\hline ST & $\begin{array}{c}-4.1 \\
(4.54)\end{array}$ & $\begin{array}{r}-15.53 \\
(2.12)\end{array}$ & $\begin{array}{c}-11.01 \\
(3.86)\end{array}$ & $\begin{array}{r}-11.54 \\
(2.76)\end{array}$ & $\begin{array}{r}10.89 \\
(6.63)\end{array}$ \\
\hline SC & $\begin{array}{l}-3.43 \\
-4.15\end{array}$ & $\begin{array}{l}-2.58 \\
(1.97)\end{array}$ & $\begin{array}{r}-13.87 \\
(3.16)\end{array}$ & $\begin{array}{l}-10.16 \\
(1.74)\end{array}$ & $\begin{array}{c}2.85 \\
(5.82)\end{array}$ \\
\hline OBC & $\begin{array}{l}-2.25 \\
(3.73)\end{array}$ & $\begin{array}{l}-2.87 \\
(1.64)\end{array}$ & $\begin{array}{l}-9.16 \\
(2.67)\end{array}$ & $\begin{array}{l}-2.99 \\
(1.35) \\
\end{array}$ & $\begin{array}{c}6.79 \\
(5.04) \\
\end{array}$ \\
\hline
\end{tabular}

S4: Controlling for Employment Characteristics and Consumption Expenditure (64678 observations)

\begin{tabular}{|c|c|c|c|c|c|}
\hline \multirow{3}{*}{ ST } & \multicolumn{4}{|c|}{ (perception gap expressed as $\%$ of UC perception) } & \multirow{3}{*}{$\begin{array}{c}\text { (percentage } \\
\text { points) } \\
13.87 \\
(6.91)\end{array}$} \\
\hline & 1.87 & -12.6 & -7.92 & -8.52 & \\
\hline & $(4.86)$ & $(2.18)$ & $(3.94)$ & $(2.83)$ & \\
\hline SC & -0.81 & -0.53 & -11.78 & -8.21 & 3.29 \\
\hline & $(4.21)$ & $(1.99)$ & $(3.23)$ & $(1.78)$ & $(5.90)$ \\
\hline OBC & $\begin{array}{c}0.18 \\
(3.80)\end{array}$ & $\begin{array}{l}-1.44 \\
(1.66)\end{array}$ & $\begin{array}{c}-8.8 \\
(2.61)\end{array}$ & $\begin{array}{l}-2.08 \\
(1.35)\end{array}$ & $\begin{array}{c}8.34 \\
(5.05)\end{array}$ \\
\hline
\end{tabular}

Standard errors in parentheses, clustered at the village (rural areas) or block (urban areas). 
Table 4B: Differential Effects of MGNREGS on Perceptions

(Phase I \& II versus Phase III)

\begin{tabular}{|c|c|c|c|c|c|}
\hline & \multicolumn{2}{|c|}{ Phase I and II } & \multicolumn{2}{|c|}{ Phase III } & \multirow[b]{2}{*}{ Impact Estimate } \\
\hline & 2009-10 & $2004-5$ & 2009-10 & $2004-5$ & \\
\hline \multicolumn{6}{|c|}{$\begin{array}{l}\text { S2: Not Controlling for Employment Characteristics and Consumption Expenditure } \\
\text { (65150 observations) }\end{array}$} \\
\hline & (percep & ap expre & $\mathrm{s} \%$ of $\mathrm{U}$ & eption) & (percentage points) \\
\hline \multirow[t]{2}{*}{ ST } & -10.92 & -15.54 & -0.57 & -9.3 & -4.1 \\
\hline & $(3.20)$ & $(2.05)$ & $(5.35)$ & $(2.95)$ & $(5.97)$ \\
\hline \multirow[t]{2}{*}{ SC } & -6.5 & -3.56 & -14.89 & -11.22 & 0.73 \\
\hline & -3.15 & (1.83) & $(3.38)$ & $(1.88)$ & $(4.53)$ \\
\hline \multirow[t]{2}{*}{ OBC } & -3.68 & -2.04 & -10.72 & -3.87 & 5.21 \\
\hline & $(2.81)$ & $(1.45)$ & $(2.31)$ & $(1.53)$ & $(2.57)$ \\
\hline
\end{tabular}

S4: Controlling for Employment Characteristics and Consumption Expenditure (64988 observations)

\begin{tabular}{|c|c|c|c|c|c|}
\hline \multirow[b]{2}{*}{ ST } & \multicolumn{4}{|c|}{ (perception gap expressed as \% of UC perception) } & \multirow{2}{*}{$\begin{array}{c}\text { (percentage points) } \\
-3.21 \\
(6.09)\end{array}$} \\
\hline & $\begin{array}{l}-6.41 \\
(3.39)\end{array}$ & $\begin{array}{l}-12.51 \\
(2.12)\end{array}$ & $\begin{array}{c}2.78 \\
(5.39)\end{array}$ & $\begin{array}{l}-6.53 \\
(2.98)\end{array}$ & \\
\hline $\mathrm{SC}$ & $\begin{array}{l}-4.44 \\
(3.21)\end{array}$ & $\begin{array}{l}-1.38 \\
(1.87)\end{array}$ & $\begin{array}{l}-12.45 \\
(3.46)\end{array}$ & $\begin{array}{l}-9.41 \\
(1.91)\end{array}$ & $\begin{array}{c}-0.02 \\
(4.64)\end{array}$ \\
\hline OBC & $\begin{array}{l}-2.3 \\
(2.80)\end{array}$ & $\begin{array}{l}-0.73 \\
(1.46)\end{array}$ & $\begin{array}{l}-10.08 \\
(2.30)\end{array}$ & $\begin{array}{l}-2.95 \\
(1.52)\end{array}$ & $\begin{array}{c}5.56 \\
(2.59)\end{array}$ \\
\hline
\end{tabular}

Standard errors in parentheses, clustered at the village (rural areas) or block (urban areas). 
Table 5: Differential Effects of Pro-Dalit Party on Perceptions (UP versus MP)

\begin{tabular}{|c|c|c|c|c|c|}
\hline & \multicolumn{2}{|c|}{ Uttar Pradesh (UP) } & \multicolumn{2}{|c|}{ Madhya Pradesh (MP) } & \multirow[b]{2}{*}{ Impact Estimate } \\
\hline & 2009-10 & 2004-5 & 2009-10 & 2004-5 & \\
\hline \multicolumn{6}{|c|}{$\begin{array}{l}\text { S2: Not Controlling for Employment Characteristics and Consumption Expenditure } \\
\text { (13971 observations) }\end{array}$} \\
\hline & (percep & p expres & $\%$ of UC & eption) & (percentage points) \\
\hline \multirow[t]{2}{*}{ SC } & -15.25 & -4.09 & -40.97 & 1.87 & 31.67 \\
\hline & $(4.56)$ & $(2.98)$ & (6.36) & $(4.67)$ & $(9.53)$ \\
\hline \multirow[t]{2}{*}{ OBC } & -16.00 & -4.36 & -21.01 & -2.62 & 6.76 \\
\hline & $(3.56)$ & $(2.27)$ & $(6.21)$ & $(3.28)$ & $(8.16)$ \\
\hline
\end{tabular}

S4: Controlling for Employment Characteristics and Consumption Expenditure (13926 observations)

\begin{tabular}{l|lllc|c}
\hline \multirow{3}{*}{ SC } & \multicolumn{4}{|l|}{ (perception gap expressed as \% of UC perception) } & (percentage points) \\
& -11.77 & -0.51 & -35.84 & 5.10 & 29.69 \\
OBC & $(4.88)$ & $(3.12)$ & $(6.93)$ & $(4.83)$ & $(10.10)$ \\
& -14.54 & -2.24 & -16.45 & 0.89 & 5.04 \\
& $(3.49)$ & $(2.29)$ & $(6.47)$ & $(3.34)$ & $(8.33)$ \\
\hline
\end{tabular}

Standard errors in parentheses, clustered at the village (rural areas) or block (urban areas).

Table 6: Inference about Actual Earnings

\begin{tabular}{c|c|c}
\hline $\begin{array}{c}\text { Whether } \\
\text { Earnings } \\
\text { Remunerative? }\end{array}$ & $\begin{array}{c}\text { Amount Perceived } \\
\text { to be Remunerative }\end{array}$ & $\begin{array}{c}\text { Inference } \\
\text { about Actual Earnings }\end{array}$ \\
\hline Yes & $\begin{array}{c}\text { Less than or equal to Rs. } 1000 \\
\text { No }\end{array}$ & $\begin{array}{c}\text { Less than or equal to Rs. } 1000 \\
\text { Less than or equal to Rs. } 1000\end{array}$ \\
No & Rs. 1001 to Rs. 1500 & Less than or equal to Rs. 1000 \\
Yes & Rs. 1001 to Rs. 1500 & Rs. 1001 to Rs. 1500 \\
No & Rs. 1501 to Rs. 2000 & Less than or equal to Rs. 1500 \\
Yes & Rs. 1501 to Rs. 2000 & Rs. 1501 to Rs. 2000 \\
No & Rs. 2001 to Rs. 2500 & Less than or equal to Rs. 2000 \\
Yes & Rs. 2001 to Rs. 2500 & Rs. 2001 to Rs. 2500 \\
No & Rs. 2501 to Rs. 3000 & Less than or equal to Rs. 2500 \\
Yes & Rs. 2501 to Rs. 3000 & Rs. 2501 to Rs. 3000 \\
Yes & More than Rs. 3000 & Greater than Rs. 3000 \\
No & More than Rs. 3000 & Inconclusive \\
\hline
\end{tabular}


Table 7: Actual Monthly Earnings Distribution by Caste, Fully Self-Employed

\begin{tabular}{|c|c|c|c|c|c|}
\hline & ST & SC & OBC & $\mathbf{U C}$ & All \\
\hline & \multicolumn{5}{|c|}{ 2004-5 (Shares in \%) } \\
\hline Less than equal to 1000 & 29.7 & 18.8 & 16.8 & 9.9 & 15.6 \\
\hline Rs. 1001 to Rs. 1500 & 12.2 & 11.3 & 11.3 & 8.2 & 10.3 \\
\hline Less than equal to 1500 & 8.1 & 7.1 & 6.3 & 4.5 & 5.9 \\
\hline Rs. 1501 to Rs. 2000 & 8.4 & 9.0 & 9.9 & 9.2 & 9.4 \\
\hline Less than equal to 2000 & 4.5 & 6.8 & 4.9 & 3.9 & 4.8 \\
\hline Rs. 2001 to Rs. 2500 & 6.6 & 4.7 & 6.5 & 6.1 & 6.1 \\
\hline Less than equal to 2500 & 5.3 & 7.3 & 6.1 & 4.6 & 5.7 \\
\hline Rs. 2501 to Rs. 3000 & 7.0 & 6.4 & 7.8 & 7.4 & 7.4 \\
\hline More than Rs. 3000 & 8.9 & 11.5 & 16.1 & 29.3 & 19.5 \\
\hline Inconclusive & 9.2 & 17.2 & 14.3 & 17.0 & 15.2 \\
\hline \multirow[t]{2}{*}{ Total } & 100.0 & 100.0 & 100.0 & 100.0 & 100.0 \\
\hline & \multicolumn{5}{|c|}{ 2009-10 (Shares in \%) } \\
\hline Less than equal to 1000 & 6.0 & 5.8 & 3.6 & 2.3 & 3.6 \\
\hline Rs. 1001 to Rs. 1500 & 6.8 & 2.9 & 4.5 & 1.8 & 3.5 \\
\hline Less than equal to 1500 & 5.0 & 3.6 & 1.8 & 1.2 & 2.0 \\
\hline Rs. 1501 to Rs. 2000 & 10.6 & 6.0 & 6.5 & 3.1 & 5.6 \\
\hline Less than equal to 2000 & 2.4 & 2.0 & 2.2 & 1.2 & 1.9 \\
\hline Rs. 2001 to Rs. 2500 & 2.4 & 3.5 & 4.5 & 2.4 & 3.5 \\
\hline Less than equal to 2500 & 4.4 & 4.8 & 4.1 & 2.9 & 3.8 \\
\hline Rs. 2501 to Rs. 3000 & 7.9 & 8.1 & 6.7 & 4.4 & 6.2 \\
\hline More than Rs. 3000 & 30.2 & 29.1 & 36.7 & 46.8 & 38.7 \\
\hline Inconclusive & 24.5 & 34.1 & 29.5 & 33.9 & 31.2 \\
\hline Total & 100.0 & 100.0 & 100.0 & 100.0 & 100.0 \\
\hline
\end{tabular}


Table 8: Semi-Elasticity of Actual Earnings w.r.t. various Characteristics (in \%), 2004-5

\begin{tabular}{l|ccc}
\hline & S1 & S2 & S3 \\
\hline Caste (Omitted UC) & & & \\
ST & -30.25 & -20.76 & -18.02 \\
SC & $(1.78)$ & $(2.02)$ & $(2.08)$ \\
& -29.17 & -19.41 & -16.80 \\
OBC & $(1.19)$ & $(1.37)$ & $(1.40)$ \\
& -17.10 & -9.55 & -7.96 \\
\hline Female & $(30.53)$ & $(1.10)$ & $(1.12)$ \\
\hline Education (Omitted No Schooling) & -30.53 & -20.86 & -21.36 \\
Primary and Below & $(0.95)$ & $(1.11)$ & $(1.11)$ \\
\hline & No & & \\
Middle & & 9.44 & 8.21 \\
Secondary and Higher Sec. & & $(1.42)$ & $(1.39)$ \\
& & 22.51 & 19.35 \\
Above Higher Secondary & & $(1.79)$ & $(1.74)$ \\
& & 37.12 & 30.14 \\
\hline Remaining Group A controls & Yes & $(2.14)$ & $(2.03)$ \\
Remaining Group B control & No & 74.15 & 58.22 \\
Group C controls & No & Yes & $(3.66)$ \\
Group D control & No & No & Yes \\
Number of observations & 48152 & No & Yes \\
\hline Nos for Table 3 apply. & & No \\
& & & 44907 \\
\hline
\end{tabular}

Notes for Table 3 apply.

Standard errors in parentheses, clustered at the village (rural areas) or block (urban areas). 
Table 9: Semi-Elasticity of Monthly Per Capita Consumption Expenditure w.r.t. various Characteristics (in \%)

\begin{tabular}{l|ccc}
\hline & S1 & S2 & S3 \\
\hline Caste (Omitted UC) & & $\mathbf{2 0 0 4 - 5}$ & \\
ST & -35.23 & -25.17 & -23.99 \\
& $(2.01)$ & $(1.81)$ & $(1.81)$ \\
SC & -32.32 & -22.47 & -20.28 \\
& $(1.27)$ & $(1.22)$ & $(1.23)$ \\
OBC & -18.99 & -12.10 & -10.85 \\
& $(1.00)$ & $(0.92)$ & $(0.92)$ \\
Number of observations & 58589 & 54682 & 54557 \\
\hline & & $\mathbf{2 0 0 9 - 1 0}$ & \\
Caste (Omitted UC) & & & \\
ST & -32.32 & -21.95 & -20.53 \\
& $(2.90)$ & $(2.74)$ & $(2.75)$ \\
SC & -27.29 & -16.81 & -15.54 \\
& $(1.68)$ & $(1.64)$ & $(1.62)$ \\
OBC & -17.05 & -9.54 & -8.90 \\
Number of observations & $(1.35)$ & $(1.30)$ & $(1.30)$ \\
\hline
\end{tabular}

Full set of controls for specifications S1, S2, and S3 specified in the text, except that we do not control for household size.

Standard errors in parentheses, clustered at the village (rural areas) or block (urban areas). 
Table 10: Differential Effects of Institutions on Monthly Per Capita Consumption Expenditure

Triple Difference Estimates (percentage points)

\begin{tabular}{|c|c|c|c|}
\hline & \multicolumn{2}{|c|}{$\begin{array}{l}\text { MGNREGS } \\
\text { impact }\end{array}$} & \multirow{2}{*}{$\begin{array}{c}\begin{array}{c}\text { Pro-Dalit BSF } \\
\text { impact }\end{array} \\
\text { UP } \\
\text { versus MP }\end{array}$} \\
\hline & $\begin{array}{l}\text { Star versus } \\
\text { Non-star }\end{array}$ & $\begin{array}{c}\text { Phase I \& II versus } \\
\text { Phase III }\end{array}$ & \\
\hline \multicolumn{4}{|c|}{ S2: Not Controlling for Employment Characteristics } \\
\hline ST & $\begin{array}{l}-8.51 \\
(5.79)\end{array}$ & $\begin{array}{l}-2.81 \\
(6.14)\end{array}$ & \\
\hline SC & $\begin{array}{l}-2.36 \\
(4.39)\end{array}$ & $\begin{array}{c}6.19 \\
(3.46)\end{array}$ & $\begin{array}{c}6.90 \\
(8.76)\end{array}$ \\
\hline OBC & $\begin{array}{l}-3.13 \\
(3.69)\end{array}$ & $\begin{array}{l}-0.59 \\
(2.14)\end{array}$ & $\begin{array}{c}3.57 \\
(6.70)\end{array}$ \\
\hline $\begin{array}{l}\text { Number of } \\
\text { Observations }\end{array}$ & 65878 & 66189 & 14178 \\
\hline \multicolumn{4}{|c|}{ S3: Controlling for Employment Characteristics } \\
\hline ST & $\begin{array}{l}-8.07 \\
(5.75)\end{array}$ & $\begin{array}{l}-2.65 \\
(6.10)\end{array}$ & \\
\hline SC & $\begin{array}{l}-2.25 \\
(4.36)\end{array}$ & $\begin{array}{c}6.13 \\
(3.47)\end{array}$ & $\begin{array}{c}7.54 \\
(8.84)\end{array}$ \\
\hline OBC & $\begin{array}{l}-2.32 \\
(3.67)\end{array}$ & $\begin{array}{l}-0.38 \\
(2.15)\end{array}$ & $\begin{array}{c}4.25 \\
(6.54)\end{array}$ \\
\hline $\begin{array}{l}\text { Number of } \\
\text { Observations }\end{array}$ & 65718 & 66029 & 14136 \\
\hline
\end{tabular}

Standard errors in parentheses, clustered at the village (rural areas) or block (urban areas). 


\section{$\underline{\text { Appendix A.1 }}$}

Here we show that under the maintained assumptions, Equations (2) and (3),

$$
\theta_{k} \equiv \frac{\partial \ln E(y \mid x)}{\partial x_{k}}=\beta_{k}
$$

Proof:

$$
\begin{aligned}
& \ln y=\boldsymbol{x} \boldsymbol{\beta}+u \\
& \Rightarrow y=\exp (\boldsymbol{x} \boldsymbol{\beta}) * \exp (u) \\
& \Rightarrow E(y \mid \boldsymbol{x})=\exp (\boldsymbol{x} \boldsymbol{\beta}) * E[\exp (u)] \text { since } u \perp \boldsymbol{x} \\
& \Rightarrow E(y \mid \boldsymbol{x})=\delta \exp (\boldsymbol{x} \boldsymbol{\beta}) \text { where } \delta=E[\exp (u)] \\
& \Rightarrow \ln E(y \mid \boldsymbol{x})=\ln \delta+\boldsymbol{x} \boldsymbol{\beta} \\
& \Rightarrow \frac{\partial \ln E(y \mid x)}{\partial x_{k}}=\beta_{k}
\end{aligned}
$$

\section{$\underline{\text { Appendix A.2 }}$}

This exposition uses the potential outcome framework introduced in Rubin 1974, and is based on the discussion in Angrist and Pischke 2009 (section 3.2.3). Bad controls are those characteristics which could themselves be viewed as outcome variables. In our context, we consider land owned, educational attainment, self-employment category, industry and occupation of employment, and household's consumption expenditure to be partly determined by an individual's caste, and are therefore bad controls. Here we use industry of employment to sign the bias arising from inclusion of these controls. For simplicity, both caste and industry are considered dichotomous.

Let $h_{i}$ denote individual $i^{\prime} s$ caste $\left(h_{i}=1\right.$ if high caste, $h_{i}=0$ if low caste), and $s_{i}$ his industry of employment $\left(s_{i}=1\right.$ if employed in the high paying service industry, $s_{i}=0$ if employed in the low paying non-service industry). As before, $y_{i}$ denotes his self-reported perception. Let $y_{1 i}$ and $y_{0 i}$ be his potential perceptions indexed by $h$. Similarly, let $s_{1 i}$ and $s_{0 i}$ be potential industry statuses also indexed by $h$. We have,

$$
\begin{aligned}
& y_{i}=h_{i} y_{1 i}+\left(1-h_{i}\right) y_{0 i} \\
& s_{i}=h_{i} s_{1 i}+\left(1-h_{i}\right) s_{0 i}
\end{aligned}
$$

Assuming that caste is exogenously assigned and is independent of potential outcomes, its causal impact on $y_{i}$ and $s_{i}$ is given by: 


$$
\begin{aligned}
& E\left(y_{i} \mid h_{i}=1\right)-E\left(y_{i} \mid h_{i}=0\right)=E\left(y_{1 i}-y_{0 i}\right) \\
& E\left(s_{i} \mid h_{i}=1\right)-E\left(s_{i} \mid h_{i}=0\right)=E\left(s_{1 i}-s_{0 i}\right)
\end{aligned}
$$

To see that $s_{i}$ is a bad control, consider the difference in mean perceptions between high castes and low castes conditional on being employed in the high paying service industry:

$$
\begin{gathered}
E\left(y_{i} \mid s_{i}=1, h_{i}=1\right)-E\left(y_{i} \mid s_{i}=1, h_{i}=0\right) \\
=E\left(y_{1 i} \mid s_{1 i}=1, h_{i}=1\right)-E\left(y_{0 i} \mid s_{0 i}=1, h_{i}=0\right) \\
=E\left(y_{1 i} \mid s_{1 i}=1\right)-E\left(y_{0 i} \mid s_{0 i}=1\right) \text { since } h_{i} \text { is exogenous } \\
=\left[E\left(y_{1 i} \mid s_{1 i}=1\right)-E\left(y_{0 i} \mid s_{1 i}=1\right)\right]+\left[E\left(y_{0 i} \mid s_{1 i}=1\right)-E\left(y_{0 i} \mid s_{0 i}=1\right)\right]
\end{gathered}
$$

The first term in square brackets is the causal effect, while the second is the selection bias. If the high paying service industry is typically the domain of higher castes, then someone who is employed in the service industry in spite of being lower caste $\left(s_{0 i}=1\right)$, is perhaps especially talented. We would therefore expect the selection bias term to be negative. Using similar derivations, it can be shown that the selection bias for all other characteristics is also negative.

\section{$\underline{\text { Appendix A.3 }}$}

Here we derive the expression for the effect of MGNREGS on `average perception gap between SC and UC' for the triple difference specification in Equation (4). The average perception gap between SC and UC in 2009/10 in Star states (expressed as percentage of UC perception in 2009/10 in Star States) is given by:

$$
\begin{aligned}
& {\left[E\left(y \mid x_{1}, S T=0, S C=1, O B C=0, \text { Year } 09=1, \text { Star }=1\right)\right.} \\
& \frac{\left.-E\left(y \mid x_{1}, S T=0, S C=0, O B C=0, \text { Year } 09=1, \text { Star }=1\right)\right]}{E\left(y \mid x_{1}, S T=0, S C=0, O B C=0, \text { Year } 09=1, \text { Star }=1\right)} * 100 \\
& =\left[\exp \left(\gamma_{2}+\gamma_{7}+\gamma_{10}+\gamma_{14}\right)-1\right] * 100
\end{aligned}
$$

The average perception gap between SC and UC in 2004/05 in Star states (expressed as percentage of UC perception in 2004/05 in Star states) is given by:

$$
\begin{aligned}
& {\left[E\left(y \mid x_{1}, S T=0, S C=1, O B C=0, \text { Year } 09=0, \text { Star }=1\right)\right.} \\
& \frac{\left.-E\left(y \mid x_{1}, S T=0, S C=0, O B C=0, \text { Year } 09=0, \text { Star }=1\right)\right]}{E\left(y \mid x_{1}, S T=0, S C=0, O B C=0, \text { Year } 09=0, \text { Star }=1\right)} * 100 \\
& =\left[\exp \left(\gamma_{2}+\gamma_{7}\right)-1\right] * 100
\end{aligned}
$$

Thus, the change over time in average perception gap between the two groups in Star states (expressed in percentage points) is given by: 


$$
\begin{aligned}
& A 3.1-A 3.2 \\
& =\exp \left(\gamma_{2}+\gamma_{10}\right)\left[\exp \left(\gamma_{7}+\gamma_{14}\right)-1\right] * 100
\end{aligned}
$$

Similarly, the average perception gap between SC and UC in 2009/10 in non-Star states (expressed as percentage of UC perception in 2009/10 in non-Star states) is given by:

$$
\begin{aligned}
& {\left[E\left(y \mid \boldsymbol{x}_{1}, S T=0, S C=1, O B C=0, \text { Year } 09=1, \text { Star }=0\right)\right.} \\
& \frac{\left.-E\left(y \mid \boldsymbol{x}_{1}, S T=0, S C=0, O B C=0, \text { Year } 09=1, \text { Star }=0\right)\right]}{E\left(y \mid \boldsymbol{x}_{1}, S T=0, S C=0, O B C=0, \text { Year } 09=1, \text { Star }=0\right)} * 100 \\
& =\left[\exp \left(\gamma_{2}+\gamma_{7}\right)-1\right] * 100
\end{aligned}
$$

The average perception gap between SC and UC in 2004/05 in non-Star states (expressed as percentage of UC perception in 2004/05 in non-Star states) is given by:

$$
\begin{aligned}
& {\left[E\left(y \mid x_{1}, S T=0, S C=1, O B C=0, \text { Year } 09=0, \text { Star }=0\right)\right.} \\
& \frac{\left.-E\left(y \mid x_{1}, S T=0, S C=0, O B C=0, \text { Year } 09=0, \text { Star }=0\right)\right]}{E\left(y \mid x_{1}, S T=0, S C=0, O B C=0, \text { Year } 09=0, \text { Star }=0\right)} * 100 \\
& =\left[\exp \left(\gamma_{2}\right)-1\right] * 100
\end{aligned}
$$

Thus, the change over time in average perception gap between the two groups in non-Star states (expressed in percentage points) is given by:

$$
\begin{aligned}
& A 3.4-A 3.5 \\
& =\exp \left(\gamma_{2}\right)\left[\exp \left(\gamma_{7}\right)-1\right] * 100
\end{aligned}
$$

Therefore the difference in 'change over time in average perception gap between the two groups' between Star and non-Star states is given by:

$$
\begin{aligned}
& A 3.3-A 3.6 \\
& \begin{array}{c}
=\exp \left(\gamma_{2}\right)\left[\exp \left(\gamma_{7}+\gamma_{10}+\gamma_{14}\right)-\exp \left(\gamma_{7}\right)-\exp \left(\gamma_{10}\right)+1\right] \\
* 100
\end{array}
\end{aligned}
$$

This is the effect of introduction of MGNREGS on average perception gap between SC and UC. 
